\title{
Management of Verticillium Wilt of Potato with Disease-Suppressive Green Manures and as Affected by Previous Cropping History
}

Robert P. Larkin, C. Wayne Honeycutt, and O. Modesto Olanya, United States Department of Agriculture-Agricultural Research Service, New England Plant, Soil, and Water Laboratory, Orono, ME 04469

\begin{abstract}
Larkin, R. P., Honeycutt, C. W., and Olanya, O. M. 2011. Management of Verticillium wilt of potato with disease-suppressive green manures and as affected by previous cropping history. Plant Dis. 95:568-576.

The ability of disease-suppressive rotation crops to reduce potato disease problems and increase crop productivity in a field with prior severe Verticillium wilt, as well as the potential influence of previous cropping history on disease suppression, was evaluated over three field seasons in Maine. Disease-suppressive rotations consisted of: (i) a high-glucosinolate mustard blend ('Caliente 119') as a mixture of white mustard (Sinapis alba) and oriental mustard (Brassica juncea) with known biofumigation potential and (ii) a sorghum-sudangrass hybrid. Each were grown as single-season green manures followed by a subsequent potato crop. These rotations were compared with a standard barley rotation and a barley rotation followed by chemical fumigation with metam sodium as controls. Both green manure rotations significantly reduced (average reductions of 25 and 18\%, respectively) Verticillium wilt in the subsequent potato crop compared with the standard barley control but were not as effective as chemical fumigation ( $35 \%$ reduction). The mustard blend also reduced other soilborne dis-

eases (black scurf and common scab) better than all other rotations Mustard blend and chemical fumigation treatments increased tuber yield relative to the barley control by 12 and $18 \%$, respectively. However, by the second rotation cycle, disease levels were high in all rotations, and only chemical fumigation resulted in substantial disease reduction $(35 \%)$. Rotations also had significant effects on soil microbiology, including soil bacterial and fungal populations and microbial community characteristics based on fatty acid profiles. However, only chemical fumigation significantly reduced soil populations of Verticillium spp. and increased general soil microbial activity. Previous cropping history did not significantly affect disease reduction, tuber yield, or soil microbial communities. This research indicates the potential for using disease-suppressive rotations for managing Verticillium wilt and other soilborne diseases but also indicates that multiple years of disease-suppressive crops may be needed to substantially reduce disease in heavily infested fields.
\end{abstract}

Verticillium wilt, caused primarily by Verticillium dahliae Kleb., is one of the most important soilborne plant diseases around the world, affecting numerous different types of crop and ornamental plants and resulting in billions of dollars in economic damage (34). In potato production, Verticillium wilt is present throughout most potato-growing areas and results in substantial yield losses $(36,37)$. Although quite lethal alone, Verticillium wilt is also known to occur in conjunction with several other pests, pathogens, and diseases, including root lesion nematode, black dot (caused by Colletotrichum coccodes), Fusarium spp., and Erwinia spp., forming a disease complex known as potato early dying $(36,37)$. Control of the Verticillium wilt pathogen is particularly difficult due to its wide host range and the production of hardy resting structures called microsclerotia that can persist in the soil for over a decade $(37,42)$. Traditionally, control has focused on reducing the populations of microsclerotia in the soil, primarily through the use of chemical fumigants such as methyl bromide and metam sodium. However, the high cost, potential negative health and environmental effects, and somewhat inconsistent efficacy of fumigation, as well as the worldwide phaseout of several effective fumigants, has led to increased attention on alternative methods of control for this disease $(9,33,37)$. Previous research on the use of organic

Corresponding author: R. Larkin, E-mail: Bob.Larkin@ars.usda.gov

Mention of trade names or commercial products in this article is solely for the purpose of providing specific information and does not imply recommendation or endorsement by the United States Department of Agriculture.

Accepted for publication 4 January 2011.

doi:10.1094/PDIS-09-10-0670

This article is in the public domain and not copyrightable. It may be freely reprinted with customary crediting of the source. The American Phytopathological Society, 2011. amendments, including animal and green manures, and diseasesuppressive crop rotations, has led to some very interesting and promising results. The use of soil amendments and nonchemical approaches to the management of Verticillium wilt have been the subject of recent reviews $(17,27,28)$.

Organic amendments, including chicken manure, liquid swine manure, and ammonium lignosulfonate, have been shown to reduce populations of $V$. dahliae and reduce Verticillium wilt; however, the specific results and active mechanisms depend on the particular soil and environmental conditions $(6-8,27,41)$. Green manures of various crop plants, including sudangrass, rapeseed, broccoli, winter pea, corn, oat, rye, and buckwheat, have all had significant effects in reducing Verticillium wilt in specific field studies $(9,11,33,43,45)$. Crops in the Brassicaceae family (which include broccoli, cabbage, cauliflower, turnip, radish, canola, rapeseed, and various mustards), in particular, used in rotations or as green manures, have been observed to reduce soilborne diseases or populations of fungal pathogens and nematodes $(3,22,30,40)$, and to improve soil characteristics and crop yield (32). Sudangrass and sorghum-sudangrass hybrids have also been shown to reduce soilborne diseases, and have been particularly effective against Verticillium wilt in previous studies (9-11). Both of these groups act through biofumigation, which refers to the breakdown of plant metabolites in soil to produce volatile compounds that are toxic to many soil microorganisms, as well as nematodes and weed seed (38). Further studies have indicated that additional mechanisms, including specific changes in soil microbial communities unrelated to levels of toxic metabolites, are also important in the reduction of soilborne diseases by these crops $(5,22,31)$. Thus, monitoring effects on soil microbial communities may also be important for understanding mechanisms and effects on diseases.

Due to differences in environmental conditions, soil types, and market and production constraints, potato production in the northeastern United States is somewhat different than in many other potato-growing regions, such as the western United States and 
Canada. Production in the northeast is characterized by cool, humid conditions, rain-fed production systems, rocky soils, moderate yield potential, high disease pressure, and low profitability (39). Most of the previous research on the use of green manures to reduce Verticillium wilt has been conducted in the western United States under very different conditions from those in the northeast, and additional research under these production conditions is needed. Although Verticillium wilt is not as prevalent in the northeastern United States as in other potato-growing regions, it still can be a major problem when it does become established in a particular field. Other important soilborne potato diseases that are persistent problems and that also need to be considered when evaluating alternative disease control approaches include black scurf caused by Rhizoctonia solani Kühn and common scab caused by Streptomyces scabiei (Thaxter) Lambert \& Loria, both of which are tuber diseases.

In our own previous research, Brassica spp. rotations and green manures have successfully reduced multiple soilborne diseases at multiple locations and in multiple trials $(22,23,25,26)$. However, these previous disease trials did not include evaluations on Verticillium wilt. As part of an earlier long-term potato rotation study, we evaluated seven different 2-year rotations for their effects on soilborne diseases and tuber yield (25). During the course of that study, Verticillium wilt, which was not present at the beginning or early years of the study, began to build up over the years until, by the fourth rotation cycle (8 years), Verticillium wilt was a substantial problem and the major factor limiting potato production in these fields. Although there were some differences among the rotations, Verticillium wilt levels were high in all rotations and in all plots, to the point that the study had to be terminated. In these fields, Verticillium wilt was determined to be associated primarily with $V$. dahliae and was not associated with any other pests or pathogens commonly associated with potato early dying, such as root lesion nematode or black dot. For the present research, we went back into these same fields and evaluated the use of selected disease-suppressive rotation crops compared with a standard rotation crop and chemical fumigant as controls. Because we already had these plots with known cropping history and demonstrated that the crop rotations greatly affected soil microbial communities, we were also interested in evaluating whether the previous cropping history would influence the potential for disease reduction and yield by the new rotation treatments. In order to also assess the influence of these previous long-term rotations on disease development or reduction, we implemented the new treatments over the existing plots, retaining the original cropping system plots. Thus, in this research, we evaluated the use of mustard blend and sudangrass green manure rotation crops in relation to a standard barley rotation crop and chemical fumigant controls for the reduction of Verticillium wilt in potato crops over a total of 3 years. Effects on other soilborne diseases, tuber yield, and soil microbial community characteristics were also evaluated, in addition to the influence of previous cropping history..

\section{Materials and Methods}

Field site and sampling. Four rotation treatments were established in research plots at a United States Department of Agriculture field site in Newport, $\mathrm{ME}\left(44^{\circ} 52^{\prime} \mathrm{N}, 69^{\circ} 17^{\prime} \mathrm{W}\right)$ in 2006 . This study was laid over the top of a previous study that examined seven different 2-year rotations in two adjacent fields over a period of 10 years (25), such that each new rotation treatment would cut across plots from each previous cropping system equally, and previous plots (representing previous cropping history) could still be maintained (Fig. 1). In the initial study, plots were established in 1997 and 1998 to study the effects of different 2-year rotations on various aspects of potato production. Soil type at the site is a Nokomis sandy loam, a coarse-loamy, mixed, frigid, Typic Haplorthod. Initial experiments were set up as randomized complete block designs consisting of four replicate plots $(24.4$ by $3.7 \mathrm{~m}$ ) for each of seven 2 -year rotations. To accommodate the need for potato crop data each year, two identical field experiments (same experimental design and 2-year rotations) were established in separate but adjacent fields in 1997 and 1998, respectively. Thus, between the two fields, both potato and rotation crops were grown each year .Crops used in these rotation studies included canola (Brassica napus L.), rapeseed (B. napus 'Dwarf Essex'), green bean (Phaseolus vulgaris L.), soybean (Glycine max L.), sweet corn (Zea mays L.), and a standard rotation of barley (Hordeum vulgare L.) underseeded with red clover (Trifolium pratense L.), as well as a continuous potato (nonrotation) control. These rotations were maintained through 2006, for a total of 10 years (and five rotation cycles) in the first field (established in 1997) and 8 years (four rotation cycles) in the adjacent field (established in 1998). After that, the current study rotation treatments were superimposed on this previous experiment.

Experimental design of the current study was a split block with four replicate blocks, each block consisting of 28 plots (four rotations $\times$ seven previous cropping histories, 3.6 by $6.1 \mathrm{~m}$ each), with previous cropping system being the main plot and the new rotations being the split-block factors (Fig. 1). The new rotation treatments consisted of: (i) a high-glucosinolate mustard blend ('Caliente 119') as a mixture of white mustard (Sinapis alba L.) and

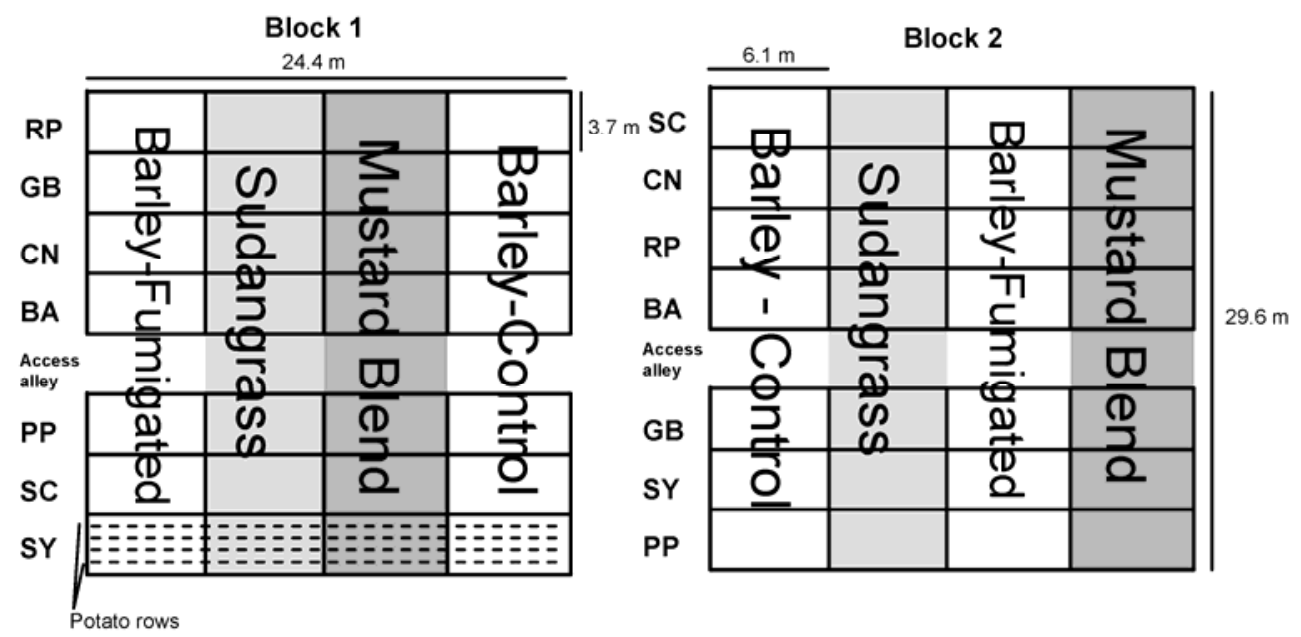

Fig. 1. Field plot layout showing previous cropping treatment arrangement (horizontal across plots) and new rotation treatments (vertical across plots) of mustard blend, sudangrass, barley-control, and barley-fumigated, for two blocks of one field. After one season of rotation treatments, all plots were planted to potato the following year (2year rotations). Actual study consisted of two identical field experiments with four blocks each, with one field planted to rotation treatments in 2006 and potato in 2007 , and the other field planted to rotation treatments in 2007 and potato in 2008. Previous cropping treatments: $\mathrm{BA}=$ barley, $\mathrm{CN}=$ canola, $\mathrm{RP}=$ rapeseed, $\mathrm{GB}=$ green bean, $\mathrm{SC}=$ sweet corn, $\mathrm{SY}=$ soybean, and $\mathrm{PP}=$ continuous potato . 
oriental mustard (B. juncea L.) with known biofumigation potential; (ii) a sorghum-sudangrass hybrid (Sorghum bicolor $\times$ S. bicolor var. sudanense L.); (iii) barley (H. vulgare L.), representing a standard rotation crop control; and (iv) a barley rotation supplemented by chemical fumigation with metam sodium. The plot and treatment arrangement for a representative section of one field is depicted in Figure 1. Both fields used in the previous study were continued as 2-year rotations, with the new rotations implemented in 2006 and 2007 in each field, respectively, followed by the potato crops in 2007 and 2008. The rotations were continued such that the 2009 potato crop in field 1 represented the second rotation cycle (two full rotation-potato cycles).

The mustard and sudangrass were grown as green manures. They were planted in June (seeding rates of 11 and $56 \mathrm{~kg} / \mathrm{ha}$, respectively), and flail mowed and rototilled into the soil in August. Barley was planted (seeding rate $140 \mathrm{~kg} / \mathrm{ha}$ ) as a standard rotation crop. Chemical fumigation using metam sodium (Vapam HL; Amvac Chemical Corp., Los Angeles) was applied at 467 liters/ha and incorporated, and the soil was packed with a roller under moist soil conditions in the fall, following barley harvest. Potato was planted in all rotation plots the following year.

Tillage for all plots prior to planting potato consisted of primary tillage in the spring with a chisel plow and then secondary tillage of one to two diskings prior to planting. Cut seed pieces of 'Russet Burbank' potato were planted by hand in each plot (four rows, 0.9 $\mathrm{m}$ between rows, with a $35-\mathrm{cm}$ spacing between plants) in May. Potato plots were fertilized with the equivalent of $\mathrm{N}$ at $224 \mathrm{~kg} \mathrm{ha}^{-1}$ and $\mathrm{P}_{2} \mathrm{O}_{5}$ and $\mathrm{K}_{2} \mathrm{O}$ at $249 \mathrm{~kg} \mathrm{ha}^{-1}$. In-season cultivation included one or two shallow passes with a cultivator and one pass with a hiller. Potato plots were also sprayed regularly throughout the growing season with alternating applications of mancozeb and chlorothalonil at recommended rates for the control of late blight. Data were collected for the potato years for each of three seasons (2007-2009, with potato planted in field 1 in 2007 and 2009 and field 2 in 2008). Changes in field usage plans precluded continuing the study for additional years.

Soil samples were collected from each plot in 2006, following the previous study and prior to implementation of the present study, and in the spring of 2007 and 2008 (following rotation treatments but prior to planting potato). Soil samples consisted of eight soil cores ( 15 by $2 \mathrm{~cm}$ in diameter) taken from the middle two rows or the middle 2-m section for crops with closer spacing and many rows. All eight cores were combined to make one composite soil sample per plot at each sampling date. Upon return from the field, soil samples were passed through a $3.35-\mathrm{mm}$ sieve to remove rocks and large organic debris. Samples were stored in plastic bags at $10^{\circ} \mathrm{C}$ and processed within 1 to 4 weeks after sampling. Soil microbial analyses were conducted on every soil sample, with three subsamples processed from each composite soil sample for most assays.

Soilborne potato disease and tuber yield. Potato plants were monitored in the field for signs and symptoms of Verticillium wilt as well as other soilborne diseases. When symptoms of early dying (wilt, chlorosis, defoliation, and premature senescence) were observed in the field, wilt severity was visually assessed in each plot on a scale of 0 to $100 \%$ (where $0 \%=$ no symptoms, $50 \%=$ half of all plants and foliage senescent or wilted, and $100 \%=$ all foliage wilted, no green plant material). At this time, plant (stem) samples were also collected from selected plants in each plot, surface sterilized in $0.5 \% \mathrm{NaOCl}$, rinsed in sterile water, cut into sections, and plated on semiselective Verticillium medium NP-10 (18) for verification of vascular infection by $V$. dahliae. Identification as $V$. dahliae was determined by its presence within vascular tissue, colony morphology, and the occurrence of typical $V$. dahliae microsclerotia in culture.

In October of each year, potato tubers were harvested from rows 2 and 3 of each plot $(12.2 \mathrm{~m})$. Tubers were washed and graded. Yield was evaluated as the total weight of tubers per hectare and marketable weight as the total weight of tubers greater than $114 \mathrm{~g}$ each. The percentage of obviously malformed or misshapen tubers was determined from the weight of misshapen tubers relative to the total weight of all tubers harvested. A subset of the harvested tubers, consisting of at least 30 tubers of marketable weight, was rated for incidence and severity of soilborne tuber diseases after at least 1 month in storage at $10^{\circ} \mathrm{C}$. Tuber diseases observed and rated consisted primarily of black scurf and common scab. Disease severity was determined as the approximate percent surface coverage of the visible symptoms on each tuber. Because tuber surface diseases become economically important above certain threshold values (affecting marketability, sales, etc.), disease incidence was measured as the percentage of tubers with disease severity at or above established thresholds. The threshold values used were $2 \%$ surface coverage for black scurf and $5 \%$ for common scab.

Microbial community characteristics. Soil microbial populations. General populations of culturable soil microorganisms were determined by soil dilution plating on agar media. For each of three subsamples from each composite soil sample, $10 \mathrm{~g}$ of soil was weighed and added to $90 \mathrm{ml}$ of sterile $0.2 \%$ water agar, vigorously stirred for $5 \mathrm{~min}$, and serially diluted and plated on $0.1 \%$ tryptic soy agar (TSA) for total bacterial counts as well as on potato dextrose agar (PDA) amended with $50 \mathrm{mg}$ of chlortetracycline and tergitol at $1 \mathrm{ml} \operatorname{liter}^{-1}$ for total fungal counts (24). Bacterial plates were incubated at $28^{\circ} \mathrm{C}$ for 3 days and fungal plates at $25^{\circ} \mathrm{C}$ for 7 days, prior to enumeration of viable colonies. Colonies of Trichoderma spp. were identified on fungal plates by their distinctive morphology and enumerated separately. All microbial populations were reported as CFU per gram of soil.

Soil populations of microsclerotia of Verticillium spp. (as an indicator of $V$. dahliae) were estimated by plating air-dried soil onto NP-10 selective medium using an Anderson Air sampler as previously described (18). Each sample consisted of five plates with approximately $0.1 \mathrm{~g}$ of soil per plate. Plates were incubated in the dark at $25^{\circ} \mathrm{C}$ for at least 4 weeks prior to enumeration of Verticillium colonies by their distinctive growth and morphology on the selective medium.

Substrate utilization profiles. The capability of soil microbial communities to utilize a variety of sole carbon sources was assessed using BIOLOG GN2 plates (BIOLOG Inc., Hayward, CA) by a procedure adapted from Garland and Mills (14) as previously described by Larkin (20). One GN2 plate was prepared for each of two soil subsamples (10 $\mathrm{g}$ of soil serially diluted as described for microbial plate counts), with $150-\mu$ aliquots of a final dilution of 1:5000 added to each of the 96 wells per plate. The plates were incubated at $22^{\circ} \mathrm{C}$ and optical density was determined on a plate reader at 590 and $760 \mathrm{~nm}$ after 72 and $96 \mathrm{~h}$ of incubation. Optical density readings were corrected for the control (blank) wells on each plate before data analyses. Substrate utilization (SU) data were also analyzed for substrate richness (the number of substrates utilized) and substrate diversity (using Shannon's diversity index). Average well color development (AWCD), calculated as the average optical density across all wells per plate, was used as an indicator of general microbial activity (20).

Fatty acid methyl ester profiles. Soil community fatty acid profiles were constructed from whole soil extractions of fatty acid methyl esters (FAMEs) according to a modification of the Microbial Identification System (MIS; MIDI, Inc., Newark, DE) standard protocol as described by Larkin (20). Extractions were conducted on each of three 4-g soil subsamples per plot. Each sample was saponified, mixed, heated, methylated, mixed, cooled, extracted, and washed as previously described (20). The organic phase was then transferred to a vial for subsequent analysis by gas chromatography using an automated procedure developed by MIDI, Inc. for an HP 6890 gas chromatograph (Hewlett-Packard, Wilmington, DE) with an HP Ultra-2 capillary column and flame ionization detector. The fatty acids were identified according to the Eukary method and naming table software developed for the MIS. The fatty acid nomenclature used is as follows: total number of carbon atoms: number of double bonds, followed by the position of the double bond from the methyl end of the molecule. Cis and trans geometry are indicated by the suffixes $\mathrm{c}$ and t. Anteiso- and 
iso-branching are indicated by the suffixes ant and iso. Only fatty acids which accounted for at least $0.25 \%$ of the total fatty acid content over all observations from any given sampling date were included in the analyses. This prevented fatty acids that were only sporadically detected or unreliably quantified from influencing the analyses $(2,20)$. In addition, dicarboxylic acids and fatty acids with a chain length of $>20$ carbons were not included in the analyses because these are generally not of microbial origin (46). With these criteria, analyses consisted of 40 to 45 unique fatty acids.

Data analyses. Soilborne disease, yield, and microbial population counts were analyzed by analysis of variance (ANOVA) with factorial treatment structure and interactions (split-block design). FAME data were analyzed by principal components analysis using the covariance matrix followed by multivariate ANOVA (16) and by canonical variates analysis, which serves to maximize differences among treatment groups (4). Data from each potato crop year were analyzed separately, and then data from 2007 and 2008, which both represent responses of the first potato crop following the single-season rotation treatments, were combined and analyzed together (with year as an additional factor and including all interactions) to evaluate cumulative and overall responses. Significance was evaluated at $P<0.05$ for all tests. Mean separation was accomplished with Fisher's protected least significant difference test. All analyses were conducted using Statistical Analysis Systems version 9.1 (SAS Institute, Cary, NC), with the general linear models procedure used for all ANOVA analyses. Most assays consisted of three subsamples and four replications (blocks). All SU data presented are based on 96-h incubation readings.

\section{Results}

Environmental conditions. Average weather conditions for each of the cropping seasons over the study period (2006-2009) were fairly typical in relation to long-term summer rainfall and temperature averages for the area (Table 1) Overall, 2006 was wetter than an average year, with abundant spring rain that continued through most of the summer, and 2007 was somewhat drier than average. Likewise, the summers of 2006 and 2008 were slightly warmer than average and 2009 slightly cooler than average. But, overall, patterns were within the normal fluctuations of yearly environmental conditions for the area and did not adversely affect crop growth or productivity for the duration of the study.

Previous cropping history effects. In general, previous cropping history (that is, whether the plots were previously cropped to barley, canola, rapeseed, sweet corn, soybean, or continuous potato prior to the implementation of the current rotation treatments) did not significantly affect Verticillium wilt, tuber yield, or other soilborne diseases. In addition, there were no significant interactions between rotation treatment and cropping history for any parameter. For example, in 2007 and 2008, Verticillium wilt levels ranged from 38 to $49 \%$ among the previous rotation crops and, although the previous barley rotation averaged at the high end and continuous potato at the low end of the range, there were no significant effects among rotations $(P=0.09)$. Likewise, total tuber yield ranged from 27 to $32 \mathrm{Mg} / \mathrm{ha}$ for the various previous rotations, with continuous potato averaging the nominally highest and rapeseed the lowest overall yield, although there was no significant previous cropping effect $(P=0.09)$. Black scurf severity ranged from 1.1 to $1.5 \%$ and common scab from 7.9 to $8.9 \%$, with no significant differences among the rotation crops $(P=0.10$ and 0.49 , respectively). However, there was a significant effect of previous cropping history on overall Trichoderma populations, with the previous rapeseed rotation averaging higher populations $\left(1.0 \times 10^{4} \mathrm{CFU} / \mathrm{g}\right.$ soil $)$ relative to continuous potato and green bean rotations $\left(0.54\right.$ to $0.57 \times 10^{4} \mathrm{CFU} / \mathrm{g}$ soil $)(P=0.007)$. All subsequent results will refer to rotation treatment effects only, without regard to previous cropping history.

Rotation treatment effects on Verticillium wilt. In the first potato crop following each single-season rotation treatment (represented by potato crop years 2007 and 2008), all rotation treatments significantly reduced the development of Verticillium wilt relative to a standard barley rotation (Table 2). The mustard blend and sudangrass green manure rotations reduced the incidence of wilt by 15 to $19 \%$ and 20 to $31 \%$ in 2007 and 2008, respectively. However, neither green manure rotation was as effective as the barley rotation fumigated with metam sodium, which reduced Verticillium wilt by 28 and $43 \%$ in 2007 and 2008, respectively. Averaged over both seasons, sudangrass, mustard, and fumigation treatments reduced wilt by 17, 24, and 35\%, respectively (Fig. 2A). In the 2009 potato crop, which represented the second rotation cycle (after the initial rotation-potato-rotation sequence), wilt was much higher in all plots and, although all the rotation treatments did still significantly reduce wilt, the green manure rotations were less effective, averaging only an 8 to $10 \%$ reduction in wilt relative to the barley control (Table 2). Fumigation resulted in a greater reduction in wilt $(35 \%)$ but wilt levels were still higher than in the previous 2 years.

Rotation treatment effects on tuber diseases. The primary potato tuber diseases observed each year were black scurf and common scab. No other tuber diseases were observed to any appreciable degree. Rotation treatments also significantly affected these tuber diseases, with the mustard blend significantly reducing incidence and severity of black scurf in 2007 and 2008 (by 13 to 31\%) and common scab in 2007 (9 to 17\%) relative to the barley standard rotation (Table 3). Fumigation reduced the incidence of black surf in 2007 and incidence and severity of black scurf in 2008 but did not affect common scab. Sudangrass reduced common scab by 5 to $14 \%$ in 2007 but did not affect black scurf in either year. Averaged over both years, mustard and fumigation treatments reduced black scurf severity by 14 and $11 \%$, respectively, and mustard and sudangrass reduced common scab severity by 11 and $8 \%$, respectively (Fig. 3).

Table 2. Development of Verticillium wilt in potato plots as affected by rotation treatment and measured as the degree of symptom development (percentage of wilting, senescence, and defoliation over whole plots) on or around September 1 of each year ${ }^{2}$

\begin{tabular}{lccc}
\hline & \multicolumn{3}{c}{ Verticillium wilt (\%) } \\
\cline { 2 - 4 } Rotation treatment & $\mathbf{2 0 0 7}$ & $\mathbf{2 0 0 8}$ & $\mathbf{2 0 0 9}$ \\
\hline Barley control & $62.2 \mathrm{a}$ & $51.3 \mathrm{a}$ & $78.8 \mathrm{a}$ \\
Sudangrass & $52.6 \mathrm{~b}$ & $41.3 \mathrm{~b}$ & $70.7 \mathrm{~b}$ \\
Mustard blend & $50.5 \mathrm{~b}$ & $35.5 \mathrm{~b}$ & $72.8 \mathrm{~b}$ \\
Barley fumigated & $44.8 \mathrm{c}$ & $29.3 \mathrm{c}$ & $50.5 \mathrm{c}$ \\
LSD $(P=0.05)$ & 2.2 & 3.3 & 4.0 \\
\hline
\end{tabular}

${ }^{\mathrm{z}}$ Means within each column followed by the same letter are not significantly different according to Fisher's protected least significant difference (LSD) test at $P=0.05$.

Table 1. Total rainfall and average daily temperature for the months of May to September at the Newport, ME research site in 2006 to 2009 compared with long-term average (LTA) conditions

\begin{tabular}{|c|c|c|c|c|c|c|c|c|c|c|}
\hline \multirow[b]{2}{*}{ Month } & \multicolumn{5}{|c|}{ Rainfall (cm) } & \multicolumn{5}{|c|}{ Average daily air temperature $\left({ }^{\circ} \mathbf{C}\right)$} \\
\hline & 2006 & 2007 & 2008 & 2009 & LTA & 2006 & 2007 & 2008 & 2009 & LTA \\
\hline May & 11.1 & 5.9 & 4.7 & 10.0 & 9.6 & 13.0 & 12.7 & 12.0 & 11.9 & 11.7 \\
\hline June & 18.7 & 6.4 & 12.9 & 17.7 & 9.9 & 17.7 & 17.7 & 16.9 & 15.0 & 16.1 \\
\hline July & 11.5 & 4.9 & 9.8 & 14.3 & 8.7 & 21.9 & 15.4 & 21.4 & 15.8 & 19.9 \\
\hline August & 11.8 & 13.0 & 8.9 & 5.0 & 8.5 & 18.0 & 19.1 & 17.6 & 18.9 & 17.8 \\
\hline September & 7.1 & 4.0 & 15.6 & 4.0 & 9.6 & 14.8 & 15.9 & 14.5 & 13.9 & 13.3 \\
\hline Total & 60.2 & 34.1 & 52.0 & 51.0 & 46.3 & 85.4 & 80.8 & 82.4 & 75.5 & 78.7 \\
\hline
\end{tabular}


Rotation treatment effects on tuber yield. Rotation treatments significantly affected tuber yield in all years. In 2007, total tuber yield was increased by 11,23 , and $28 \%$ for sudangrass, mustard and fumigation treatments, respectively. In 2008, only fumigation significantly increased yield (by 9\%). In 2009, mustard, sudangrass, and fumigation increased yield by 6,10 , and $20 \%$, respectively. Averaged over both years representing the first rotation cycle (2007 and 2008), mustard blend and fumigation treatments increased total yield by 12 and 18\%, respectively (Fig. 2B). Marketable yield was also increased similarly by the respective rotations (Table 4).
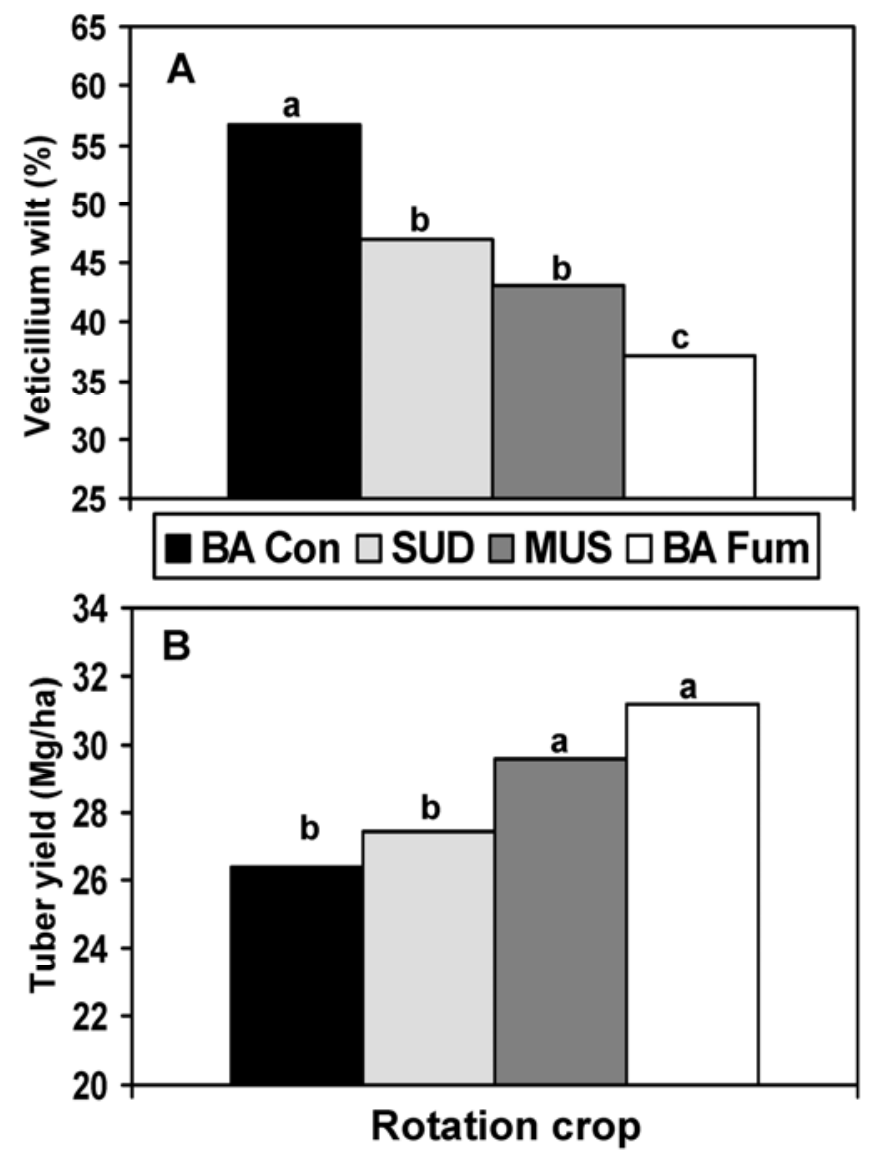

Fig. 2. Effect of disease-suppressive rotation treatments on A, the severity of Verticillium wilt (percent wilting and defoliation) and $\mathbf{B}$, total tuber yield averaged over two potato seasons (2007 and 2008). BA Con $=$ standard barley rotation (control), SUD = sudangrass green manure, MUS $=$ mustard blend green manure, BA Fum = barley rotation with fumigation by metam sodium. Bars topped by the same letter are not significantly different according to Fisher's protected least significant difference test $(P<0.05)$.
Rotation treatment effects on soil microbial communities. Various aspects of soil microbial communities, including populations of culturable bacteria and fungi, microbial activity, and soil FAME profiles, were significantly affected by rotation treatments. Although overall results were similar for both years (2007 and 2008), there were some individual differences each year. Based on average values from soil samples collected in the spring following the rotation crop and prior to planting potato, soil from the barleyfumigated rotation averaged higher general bacterial populations than all other rotations $(P=0.0001)$ in both years, and the mustard blend and sudangrass rotations had higher bacterial populations than the barley control in 2008 (Table 5). On the other hand, fungal populations were lower in soil from the barley-fumigated rotation than that of all other rotations in both years, and also lower with
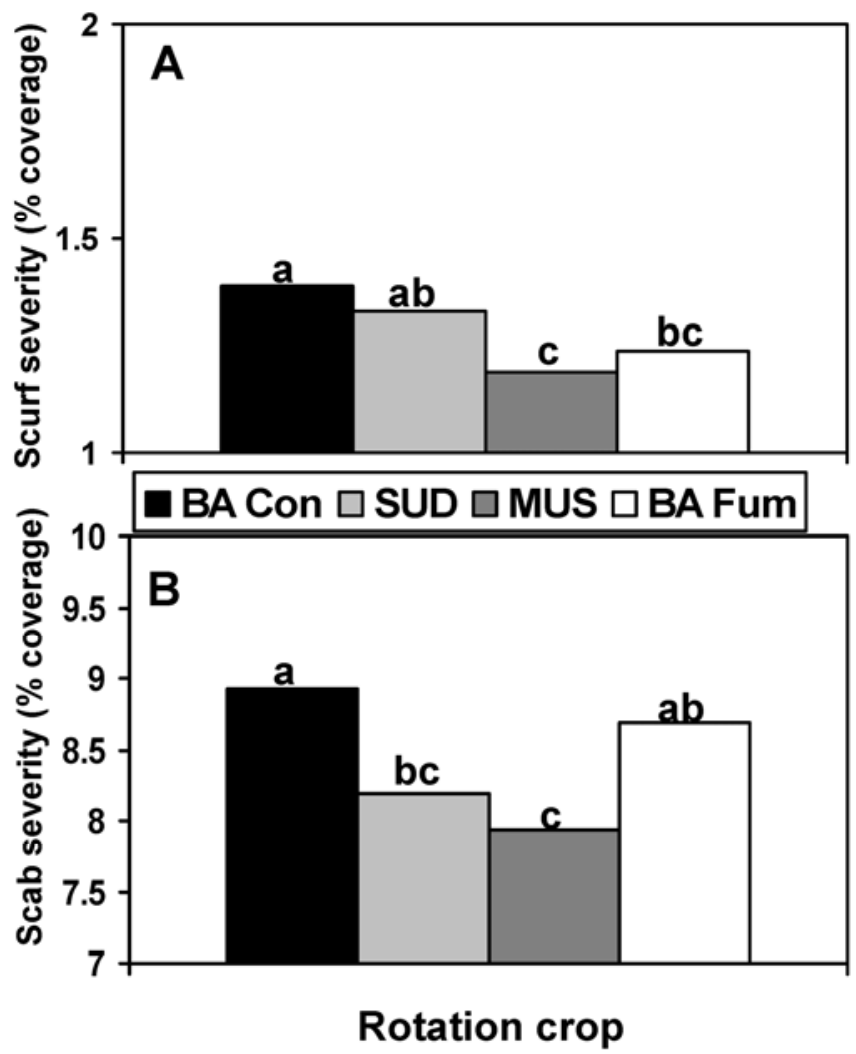

Fig. 3. Effect of disease-suppressive rotation treatments on the severity (percent surface coverage) of the tuber diseases A, black scurf and B, common scab averaged over two potato seasons (2007 and 2008). BA Con = standard barley rotation (control), SUD = sudangrass green manure, MUS = mustard blend green manure, BA Fum = barley rotation with fumigation by metam sodium. Bars topped by the same letter are not significantly different according to Fisher's protected least significant difference test $(P<0.05)$.

Table 3. Effects of different rotation treatments on the severity and incidence of the potato tuber diseases black scurf and common scab in the 2007 and 2008 potato harvests ${ }^{\mathrm{z}}$

\begin{tabular}{|c|c|c|c|c|c|c|c|c|}
\hline \multirow[b]{3}{*}{ Rotation treatment } & \multicolumn{4}{|c|}{2007} & \multicolumn{4}{|c|}{2008} \\
\hline & \multicolumn{2}{|c|}{ Black scurf (\%) } & \multicolumn{2}{|c|}{ Common scab (\%) } & \multicolumn{2}{|c|}{ Black scurf (\%) } & \multicolumn{2}{|c|}{ Common scab (\%) } \\
\hline & Severity & Incidence & Severity & Incidence & Severity & Incidence & Severity & Incidence \\
\hline Barley control & $1.49 \mathrm{a}$ & $45.2 \mathrm{a}$ & $9.44 \mathrm{a}$ & $83.3 \mathrm{a}$ & $1.29 \mathrm{a}$ & $34.7 \mathrm{a}$ & $8.51 \mathrm{a}$ & $62.8 \mathrm{a}$ \\
\hline Sudangrass & $1.45 \mathrm{a}$ & $42.8 \mathrm{ab}$ & $8.13 \mathrm{~b}$ & $78.8 \mathrm{~b}$ & $1.20 \mathrm{ab}$ & $30.1 \mathrm{a}$ & $8.25 \mathrm{a}$ & $66.5 \mathrm{a}$ \\
\hline Mustard blend & $1.29 \mathrm{~b}$ & $37.6 \mathrm{~b}$ & $7.84 \mathrm{~b}$ & $76.1 \mathrm{~b}$ & $1.09 \mathrm{bc}$ & $23.8 \mathrm{~b}$ & $8.04 \mathrm{a}$ & $62.3 \mathrm{a}$ \\
\hline Barley fumigated & $1.37 \mathrm{ab}$ & $38.3 \mathrm{~b}$ & $9.00 \mathrm{a}$ & $84.5 \mathrm{a}$ & $1.01 \mathrm{c}$ & $21.7 \mathrm{~b}$ & $8.38 \mathrm{a}$ & $65.7 \mathrm{a}$ \\
\hline $\operatorname{LSD}(P=0.05)$ & 0.14 & 5.5 & 0.63 & 3.9 & 0.13 & 5.6 & 0.65 & 5.2 \\
\hline
\end{tabular}

z Severities of black scurf and common scab were estimated based on the average percentage of tuber surface covered with lesions. Incidence refers to the percentage of tubers showing economically-important levels of disease, which was considered to be of severity greater than $2 \%$ for black scurf and severity greater than $5 \%$ for common scab. In total, 840 tubers were assessed per rotation treatment (four reps $\times 30$ tubers $\times$ seven cropping histories) per year. Means within each column followed by the same letter are not significantly different according to Fisher's protected least significant difference (LSD) test at $P=0.05$. 
mustard blend and sudangrass than in the barley control in 2007 and lower with mustard blend than sudangrass rotation in 2008 (Table 5). The effect on fungal populations was also noted in the populations of Trichoderma spp., which were lower in the fumigated plots $\left(3.1 \times 10^{3} \mathrm{CFU} / \mathrm{g}\right.$ soil $)$ but higher in the sudangrass rotation $\left(9.0 \times 10^{3} \mathrm{CFU} / \mathrm{g}\right.$ soil $)$ than in the others $\left(6.2\right.$ to $6.3 \times 10^{3}$ CFU/g soil $)(P<0.0001)$ over both years. Populations of Verticillium spp. also were lower in the fumigated rotation than the other rotations in both years but there were no other differences among rotations (Table 5). Microbial activity, as measured by average substrate usage (AWCD) on Biolog plates, was highest in soil from the fumigated rotation and lowest in sudangrass and mustard rotations (Table 5). In addition, substrate diversity (Shannon's index) was higher in both the barley rotations (4.00 and 4.01) compared with the green manures $(3.98$ and 3.97$)(P<0.001)$, whereas substrate richness, which represents the total number of different substrates effectively utilized, was higher in soil from the barley control (48.1) than all other rotation treatments $(45.7$ to 46.3$)(P<$ $0.001)$.

Baseline values from soil samples collected in 2006 following a previous potato crop and prior to the implementation of the new rotation treatments were $37.1 \times 10^{6}$ and $38.0 \times 10^{4} \mathrm{CFU} / \mathrm{g}$ soil for bacterial and fungal populations, respectively, $44.3 \mathrm{CFU} / \mathrm{g}$ soil for Verticillium spp., and 0.445 optical density for AWCD (microbial activity). Thus, microbial activity was somewhat increased and Verticillium spp. populations somewhat reduced for most rotations relative to the pre-study baseline values, whereas bacterial and fungal populations remained similar to baseline values for all but the fumigated rotation treatment.

Analysis of the soil fatty acid data indicated that soil FAME profiles were distinctly different among the different rotation treatments $(P=0.0001)$, indicating detectable changes in soil microbial community characteristics. Graphical depiction of the first two canonical variates (CV1 and CV2) from canonical variates analysis indicated that, in general, each crop rotation produced microbial characteristics distinct from each other rotation (Fig. 4). For most rotations, the effect of the rotation treatment was much stronger than that of previous cropping history, as was made evident by the greater separation of different rotation crops and closer proximity of the different cropping histories within each particular rotation treatment. However, within the barley-fumigated treatment, the plots previously cropped to barley were different than those that were previously cropped to any of the other rotation crops (Fig. 4).

Looking further at FAME profiles among the rotations, fatty acid classes and individual FAMEs representing different groups of microorganisms also differed significantly among rotations. The relative percentage of monounsaturated fatty acids, which are associated with gram-negative bacteria and mycorrhizae, as well as the percentage of polyunsaturated fatty acids, which are FAME indicators for fungi, tended to be highest in soil from the barley control plots and lowest in the mustard and barley-fumigated plots $(P<0.001)$ (data not shown). The percentage of abundance of individual FAMEs that are indicative of different microorganism groups also showed significant differences among rotation treatment. The percentage of the FAME 16:1 $\omega 5 \mathrm{c}$, which is an indicator for arbuscular mycorrhizal fungi, was significantly different with each rotation treatment, with highest levels observed in the barley control and lowest in mustard blend plots (Table 6). The percentage of 15:0 iso, an indicator for gram-positive bacteria, was highest in the mustard blend plots and lowest in both barley treatments (Table 6). The individual FAME that serves as an indicator for fungi, 18:2 $\omega 6 \mathrm{c}$, was highest in the barley control and lowest in both the mustard and fumigated plots. Another FAME marker, 18:1 $\omega 9 \mathrm{c}$, which is present primarily in gram-negative bacteria as well some fungi, tended to be highest in the mustard plots and lowest in the barley control. Another indicator of fungi, oomycetes, and protozoa, 20:5 w3c, was highest in the barley control and lowest in barley-fumigated followed by mustard blend plots (Table 6).

\section{Discussion}

In this research, single-season green manures of a mustard blend and sudangrass prior to potato crops reduced the severity of Verticillium wilt (by 8 to 31\%) and also increased tuber yield (by 2 to $23 \%$ ) relative to a standard barley rotation over multiple crop-

Table 4. Effects of different rotation treatments on total and marketable potato tuber yield in 2007, 2008, and 2009

\begin{tabular}{|c|c|c|c|c|c|c|}
\hline \multirow[b]{3}{*}{ Rotation treatment } & \multicolumn{6}{|c|}{ Tuber yield $(\mathrm{Mg} / \mathrm{ha})^{\mathrm{z}}$} \\
\hline & \multicolumn{2}{|c|}{2007} & \multicolumn{2}{|c|}{2008} & \multicolumn{2}{|c|}{2009} \\
\hline & Total & Marketable & Total & Marketable & Total & Marketable \\
\hline Barley control & $25.1 \mathrm{c}$ & $9.8 \mathrm{c}$ & $27.7 \mathrm{~b}$ & $15.0 \mathrm{~b}$ & $32.6 \mathrm{c}$ & $17.5 \mathrm{c}$ \\
\hline Sudangrass & $27.9 \mathrm{~b}$ & $14.2 \mathrm{ab}$ & $27.0 \mathrm{~b}$ & $13.9 \mathrm{~b}$ & $35.8 \mathrm{~b}$ & $20.5 b$ \\
\hline Mustard blend & $30.9 \mathrm{a}$ & $12.4 \mathrm{~b}$ & $28.2 \mathrm{~b}$ & $15.6 \mathrm{~b}$ & $34.5 \mathrm{~b}$ & $19.7 \mathrm{bc}$ \\
\hline Barley fumigated & $32.1 \mathrm{a}$ & $15.8 \mathrm{a}$ & $30.2 \mathrm{a}$ & $17.3 \mathrm{a}$ & $39.2 \mathrm{a}$ & $25.8 \mathrm{a}$ \\
\hline $\operatorname{LSD}(P=0.05)$ & 1.6 & 2.4 & 1.5 & 1.7 & 1.8 & 2.4 \\
\hline
\end{tabular}

${ }^{\mathrm{z}}$ Means within each column followed by the same letter are not significantly different according to Fisher's protected least significant difference (LSD) test at $P=0.05$.

Table 5. Effects of different rotation treatments on soil microbial characteristics, including culturable bacterial populations, fungal populations, Verticillium counts, and microbial activity measured in Spring 2007 and 2008 prior to planting potato ${ }^{y}$

\begin{tabular}{|c|c|c|c|c|c|c|c|c|}
\hline \multirow[b]{3}{*}{ Rotation treatment } & \multicolumn{4}{|c|}{$2007^{z}$} & \multicolumn{4}{|c|}{2008} \\
\hline & \multicolumn{2}{|c|}{$\begin{array}{l}\text { Bacterial populations } \\
\left(\times 10^{6} \mathrm{CFU} / \mathrm{g} \text { soil }\right)\end{array}$} & \multicolumn{2}{|c|}{$\begin{array}{c}\text { Fungal populations } \\
\left(\times 10^{4} \mathrm{CFU} / \mathrm{g} \text { soil }\right)\end{array}$} & \multicolumn{2}{|c|}{$\begin{array}{c}\text { Verticillium sp. } \\
\text { (microsclerotia/g soil) }\end{array}$} & \multicolumn{2}{|c|}{$\begin{array}{c}\text { Microbial activity } \\
\text { (AWCD, optical density) }\end{array}$} \\
\hline & 2007 & 2008 & 2007 & 2008 & 2007 & 2008 & 2007 & 2008 \\
\hline Barley control & $31.3 \mathrm{~b}$ & $35.8 \mathrm{c}$ & $38.6 \mathrm{a}$ & $39.2 \mathrm{ab}$ & $38.5 \mathrm{a}$ & $44.1 \mathrm{a}$ & $0.540 \mathrm{~b}$ & $0.533 \mathrm{c}$ \\
\hline Sudangrass & $29.5 \mathrm{~b}$ & $42.2 \mathrm{~b}$ & $33.7 \mathrm{~b}$ & $41.7 \mathrm{a}$ & $45.0 \mathrm{a}$ & $35.6 \mathrm{ab}$ & $0.452 \mathrm{c}$ & $0.559 \mathrm{~b}$ \\
\hline Mustard blend & $29.2 \mathrm{~b}$ & $45.3 \mathrm{~b}$ & $32.2 \mathrm{~b}$ & $37.9 \mathrm{~b}$ & $42.7 \mathrm{a}$ & $38.4 \mathrm{ab}$ & $0.467 \mathrm{c}$ & $0.528 \mathrm{c}$ \\
\hline Barley fumigated & $75.3 \mathrm{a}$ & $63.3 \mathrm{a}$ & $15.3 \mathrm{c}$ & $23.9 \mathrm{c}$ & $26.6 \mathrm{~b}$ & $28.7 \mathrm{~b}$ & $0.685 \mathrm{a}$ & $0.591 \mathrm{a}$ \\
\hline $\operatorname{LSD}(P=0.05)$ & 4.6 & 3.8 & 2.7 & 2.5 & 9.8 & 10.7 & 0.024 & 0.018 \\
\hline
\end{tabular}

${ }^{y}$ Means within each column followed by the same letter are not significantly different according to Fisher's protected least significant difference (LSD) test at $P=0.05$. Baseline values measured in 2006 prior to implementation of rotation treatments were $37.1 \times 10^{6}$ and $38.0 \times 10^{4} \mathrm{CFU} / \mathrm{g}$ soil, respectively, for bacterial and fungal populations, $44.3 \mathrm{CFU} / \mathrm{g}$ soil for Verticillium spp., and 0.445 optical density for average well color development (AWCD) (microbial activity).

${ }^{\mathrm{z}}$ Bacterial populations represent total culturable bacteria and fungal populations represent total culturable fungi (including Trichoderma spp.) from soil dilution plate counts on $0.1 \%$ tryptic soy agar and potato dextrose agar, respectively. 
ping seasons in a potato field severely infested with Verticillium spp.. The mustard blend resulted in slightly better disease control than sudangrass. However, the green manures were not as effective as treatment with the commercial fumigant metam sodium, which gave disease reductions of 28 to $43 \%$ and yield increases of 9 to $28 \%$. Moreover, the green manures were much less effective in the second rotation cycle (that is, in the second potato crop after the first full rotation sequence) than in the first cycle. In previous research in Idaho, Davis et al. (11) achieved good control of Verticillium wilt and increased potato yield after multiple seasons of sudangrass, rapeseed, and other green manures but with the best control observed with sudangrass. However, by the second potato crop after the manure treatments, disease control was not as effective and yields were lower (11). In a follow-up study, Davis et al. observed that one additional year of green manures restored disease control to previous levels in the next potato crop (9). However, these studies were not continued to determine whether subsequent alternating years of green manures and potato would result in sustained or declining disease control. In related studies in Oregon examining several green manures at different incorporation rates (33), single-season green manures of winter pea, broccoli, and sudangrass all substantially reduced Verticillium wilt severity when incorporated at higher rates (12 to $24 \mathrm{Mg} / \mathrm{ha}$ ) but did not increase yield.

In our studies, it was encouraging to find that, after just a single year of green manure additions to a field severely infested with Verticillium wilt, substantial disease control was observed. However, because of the very high levels of disease initially observed in these fields, it may have been more beneficial if multiple seasons of green manures were added before reintroducing potato, as in the

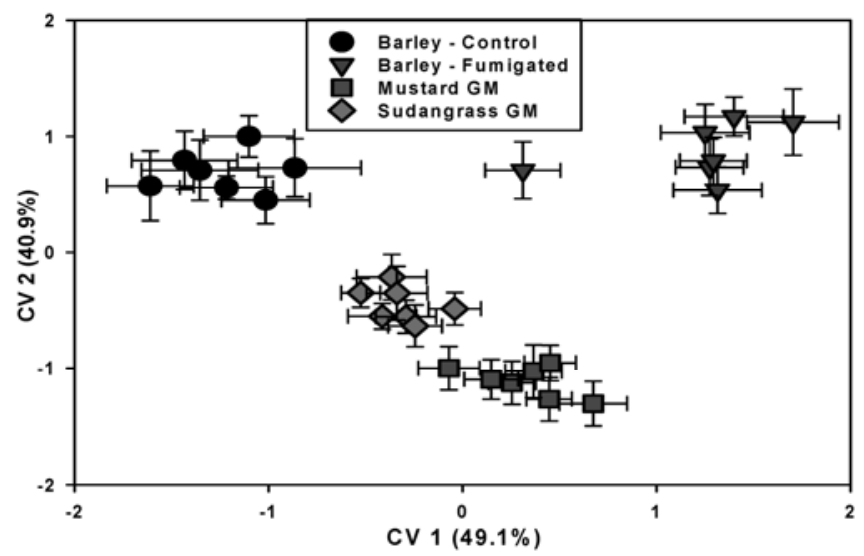

Fig. 4. Effects of different rotation treatments and previous cropping history on soil microbial community characteristics, as represented by soil fatty acid methyl ester (FAME) profile analysis (canonical variates [CVs] 1 and 2 from CV analysis of 45 FAMEs) following the rotations and prior to planting potato average values for 2007 and 2008 combined. Error bars represent the standard error of the mean. Numbers in parentheses refer to the percentage of canonical variability accounted for by each CV. initial Davis study (11). Even the chemical fumigant was only partially successful in reducing Verticillium wilt after a single treatment, because moderate wilt levels were still observed each year and, by the second potato crop, disease levels were higher than 2007 levels in all plots. For severely infested fields, multiple years of remediation treatments and removal from potato production may be needed to more substantially reduce or lessen the pathogen inoculum levels and disease pressure, regardless of treatment method.

As for other soilborne diseases observed in this study, only the mustard blend green manure treatment consistently reduced both black scurf and common scab relative to the barley control (by 9 to $31 \%$ ), whereas sudangrass had some activity against common scab and barley fumigation had some activity against black scurf. Our own previous studies have indicated that Brassica spp. rotations and green manures have consistently reduced multiple soilborne diseases, including Rhizoctonia canker, black scurf, common scab, and powdery scab, as well as often increasing yield $(22,23,25,26)$. Additional studies in Maine (39) observed that mustard blend green manures resulted in reduced incidence of black scurf and increased yield but also increased white mold at the two locations where white mold was present (common scab was not reported in these studies). The lack of control of common scab by the fumigant was not surprising, because the causal agent for common scab is an actinomycete, a bacteria, and the primary activity of these fumigants are against fungi, not bacteria, as was indicated in the general microbial counts and FAME profiles. The additional capability of the green manures to have activity against common scab is significant because common scab is also a major problem throughout the region.

Although the commonly accepted mechanism of action for disease control by Brassica crops, as well as sudangrass, is biofumigation $(3,30,40)$, there is mounting evidence that changes within soil microbial communities (that are not directly related to biofumigation compounds) may also be very important. In this study, only the fumigation treatment resulted in significant reduction of $V$. dahliae populations in the soil. The green manure treatments also reduced disease but did not reduce populations of Verticillium spp. Thus, only the fumigant treatment appeared to act primarily through the reduction of pathogen inoculum. In our previous research, Brassica green manures provided greater reductions in Rhizoctonia diseases than mustard crops with much higher glucosinolate levels, indicating that biofumigation products were not the primary mechanism of action (22). In the work of Davis et al. $(9,11)$, it was also noted that green manure treatments often did not reduce pathogen populations but did reduce pathogen infections. In that work, the mechanism of action for sudangrass and other green manures for reduction of Verticillium wilt was considered to be biological control, based on the increases in general microbial activity and increases in nonpathogenic Fusarium spp. associated with disease suppression $(9,11)$. Other studies have observed that additions of green manures often did not necessarily reduce pathogen populations or survival but did increase populations of microorganisms that were antagonistic toward the pathogens (35). Wig-

Table 6. Effects of different rotation treatments on the relative abundance (percentage of total) of indicator fatty acid methyl esters (FAMEs) 15:0 iso, 16:1 $\omega 6 \mathrm{c}, 18: 2 \omega 6 \mathrm{c}$, and 18:1 $\omega 9 \mathrm{c}$, and 20:5 $\omega 3 \mathrm{c}$ from soil samples collected in the Spring prior to planting potatoes (average values from 2007 and 2008 combined)

\begin{tabular}{lccccc}
\hline & \multicolumn{5}{c}{ Indicator FAMEs $^{\mathbf{z}}$} \\
\cline { 2 - 6 } Rotation crop & $\mathbf{1 5 : 0}$ iso & $\mathbf{1 6 : 1} \mathbf{\omega 5 \mathbf { c }}$ & $\mathbf{1 8 : 2} \mathbf{\omega 6 \mathbf { c }}$ & $\mathbf{1 8 : 1} \boldsymbol{\omega \mathbf { 9 c }}$ & $\mathbf{2 0 : 5} \boldsymbol{\omega \mathbf { 3 c }}$ \\
\hline Barley control & $4.23 \mathrm{a}$ & $4.99 \mathrm{a}$ & $5.54 \mathrm{a}$ & $2.74 \mathrm{c}$ & $0.61 \mathrm{a}$ \\
Sudangrass & $1.33 \mathrm{e}$ & $3.83 \mathrm{c}$ & $4.50 \mathrm{~b}$ & $3.91 \mathrm{ab}$ & $0.44 \mathrm{~b}$ \\
Mustard blend & $3.67 \mathrm{~b}$ & $2.74 \mathrm{~d}$ & $4.05 \mathrm{c}$ & $4.10 \mathrm{a}$ & $0.33 \mathrm{c}$ \\
Barley fumigated & $1.79 \mathrm{c}$ & $4.15 \mathrm{~b}$ & $4.10 \mathrm{c}$ & $3.61 \mathrm{~b}$ & $0.24 \mathrm{~d}$ \\
LSD $(P=0.05)$ & 0.12 & 0.23 & 0.38 & 0.38 & 0.06 \\
\hline
\end{tabular}

${ }^{\mathrm{z}}$ FAMEs that are specifically associated with particular organisms or groups are considered indicators of the relative abundance of those groups, including 15:0 iso for gram-positive bacteria, 16:1 $\omega 5 \mathrm{c}$ for mycorrhizae, 18:2 $\omega 6 \mathrm{c}$ for fungi, 18:1 $\omega 9 \mathrm{c}$ for gram-negative bacteria and certain fungi, and 20:5 $\omega 3 \mathrm{c}$ for eukaryotes (fungi, protozoa, and so on). Means within each column followed by the same letter for each variable group are not significantly different according to Fisher's protected least significant difference (LSD) test at $P=0.05$. 
gins and Kinkel (45) also noted that the disease-suppressive effects of green manures were related to changes in the activity of pathogen inhibition and soil microbial communities.

Various grass and forage crops with extensive root systems grown as rotation, cover, or green manure crops are known to increase microbial populations, activity, and diversity $(1,13,15,19)$, and effects associated with green manures are generally greater than for other (nonincorporated) rotations. In general, higher microbial activity and diversity has been associated with increased suppression of crop diseases $(13,15,44)$. In other research, incorporation of Brassica residues had greater impact on soil microbial communities than other organic amendments or Brassica residues that were not incorporated, and also more effectively reduced soilborne disease (12).

Our research (this study and previous studies) indicates that each rotation crop can impart somewhat unique microbial characteristics, or at least influence the structure and function of those microbial communities, and that Brassica crops appear to have different effects than most other crops $(20,21,23)$. In the current study, the rotation crop effects were substantially modified (in the barley rotation) by fumigation with metam sodium. The barley-fumigated soils had higher bacterial populations and microbial activity and lower fungal populations (including Verticillium and Trichoderma subpopulations), reflecting the fumigant effect of killing fungal propagules and stimulating bacterial growth with the loss of fungi and their release of available nutrients. This was also observed to a much lesser degree (slight increase in bacterial populations and decease in fungal populations) with the mustard rotation, although no corresponding reduction in Verticillium populations was observed.

FAME profiles revealed distinct differences in soil microbial community characteristics associated with each rotation. Differences in FAME profiles were related to differences within both the bacterial and fungal communities. Both of the green manure treatments resulted in somewhat similar effects on microbial communities (same types of community shifts) but these effects were very different from either of the barley rotations. High CV1 values, such as for the fumigated plots, represented generally high levels of bacterial FAMEs and low fungal FAMEs, whereas low values represented the opposite. For CV2, which separated the green manure treatments from either of the barley rotations, higher values were associated with higher levels of mycorrhizal FAMEs and lower values with higher levels of $18: 1 \omega 9 \mathrm{c}$ and gram-positive bacteria. FAME 16:1 $\omega 5 \mathrm{c}$ was important for differentiating among rotations, with the barley rotations showing high levels, indicating higher mycorrhizae populations, whereas the green manure treatments had generally low levels. Brassica crops such as mustard are known to be nonmycorrhizal and support characteristically low populations of mycorrhizae. Differences in FAME 18:2 $\omega 6 \mathrm{c}$ and other fungal-associated FAMEs also were important for distinguishing among the rotations. In potato research in Italy, fungal diversity was greater and species composition differed in longer rotations than in continuous or short-term rotations, and non-rotations resulted in increased pathogen densities (29). We are continuing to work with these systems to better understand how diseasesuppressive rotations affect soil microbial communities, and to more specifically identify what changes and microorganism groups may be responsible for disease suppression.

In this study, effects of the current rotations on soil microbial communities were much greater than the previous cropping history. In previous research, crop rotation effects on soil microbial communities were also greater than various other factors, such as additions of biocontrol organisms or biological amendments (21), cover crops (25), or irrigation (26). Overall, our results suggest that the rotation crop is a primary determinant of the microbial community structure, shaping the microbial communities, whereas other factors, such as previous rotations or other cropping practices, can modify these communities to some degree but may have a more secondary influence relative to the main rotation crop effects. For most assessed parameters, previous cropping history was not a significant factor in this study. Although each rotation crop resulted in distinctive changes in soil microbial characteristics, as well as differences in diseases and yield in the previous study (25), apparently those crop-induced changes were short-lived, and effects of the previous crops were negated or greatly reduced once the new rotation treatments were implemented.

This research indicates that the use of disease-suppressive green manures, such as mustard and sudangrass, does have potential to help reduce Verticillium wilt, as well as other soilborne diseases of potato, under the environmental and production conditions of the northeast United States. Although these rotations were not as effective as chemical fumigation, it should be noted that, under production and economic conditions in the northeast, use of chemical fumigants such as metam sodium is generally cost prohibitive and seldom used (39). Thus, the degree of control provided by green manures may provide a substantial benefit over current approaches under our production constraints. Effective rotations are important for reducing or minimizing potential soilborne disease problems but cannot, by themselves, completely control or eliminate diseases. Good rotation strategies should be used in conjunction with other crop, soil, and disease management approaches to achieve more sustainable crop production.

\section{Acknowledgments}

Many people have worked on or contributed to this research in various ways over the years of these studies, from summer workers and student aides to field crews, technicians, colleagues, and miscellaneous hands and expertise. Most importantly, we thank L. Matthiesen for her thorough and capable technical assistance on all aspects of this work; D. Torrey for managing and maintaining the field sites; P. Pinette, G. Trusty, E. Champaco, and D. Cowperthwaite for additional technical support; our fellow NEPSWL scientists J. Halloran and Z. $\mathrm{He}$, who have contributed to this research in various ways; and all the others without whom these studies could never be completed.

\section{Literature Cited}

1. Bailey, K. L., and Lazarovits, G. 2003. Suppressing soil-borne diseases with residue management and organic amendments. Soil Tillage Res. 72:169180.

2. Bossio, D. A., and Scow, K. M. 1998. Impacts of carbon and flooding on soil microbial communities: phospholipid fatty acid profiles and substrate utilization patterns. Microb. Ecol. 35:265.

3. Brown, P. D., and Morra, M. J. 1997. Control of soilborne plant pests using glucosinolate-containing plants. Adv. Agron. 61:167-231

4. Buyer, J. S., Roberts, D. P., and Russeck-Cohen, E. 1999. Microbial community structure and function in the spermosphere as affected by soil and seed type. Can. J. Microbiol. 45:138-144.

5. Cohen, M. F., Mazzola, M., and Yamasaki, H. 2005. Brassica napus seed meal soil amendment modifies microbial community structure, nitric oxide production and incidence of Rhizoctonia root rot. Soil Biol. Biochem. 37:1215-1227.

6. Conn, K. L., and Lazarovits, G. 1999. Impact of animal manures on Verticillium wilt, potato scab, and soil microbial populations. Can. J. Plant Pathol. 21:81-92.

7. Conn, K. L., and Lazarovits, G. 2000. Soil factors influencing the efficacy of liquid swine manure added to soil to kill Verticillium dahliae. Can. J. Plant Pathol. 22:400-406.

8. Conn, K. L., Tenuta, M., and Lazarovits, G. 2005. Liquid swine manure can kill Verticillium dahliae microsclerotia in soil by volatile fatty acid, nitrous acid, and ammonia toxicity. Phytopathology 95:28-35.

9. Davis, J. R., Huisman, O. C., Everson, D. O., Nolte, P., Sorensen, L. H., and Schneider, A. T. 2010. Ecological relationships of Verticillium wilt suppression of potato by green manures. Am. J. Potato Res. 87:315-326.

10. Davis, J. R., Huisman, O. C., Westermann, D. T., Everson, D. O., Schneider, A., and Sorensen, L. H. 2004. Some unique benefits with sudangrass for improved U.S.\#1 yields and size of Russet Burbank potato. Am. J. Potato Res. 81:403-413.

11. Davis, J. R., Huisman, O. C., Westermann, D. T., Hafez, S. L., Everson, D. O., Sorensen, L. H., and Schneider, A. T. 1996. Effects of green manures on Verticillium wilt of potato. Phytopathology 86:444-453.

12. Friberg, H., Edel-Hermann, V., Faivre, C., Gautheron, N., Fayolle, L., Faloya, V., Montfort, F., and Steinberg, C. 2009. Cause and duration of mustard incorporation effects on soil-borne plant pathogenic fungi. Soil Biol. Biochem. 41:2075-2084.

13. Garbeva, P., van Veen, J. A., and van Elsas, J. D. 2004. Microbial diversity in soil: selection of microbial populations by plant and soil type and implications for disease suppressiveness. Annu. Rev. Phytopathol. 42:243-270.

14. Garland, J. L., and Mills, A. L. 1991. Classification and characterization of heterotrophic microbial communities on the basis of patterns of communitylevel sole-carbon-source utilization Appl. Environ. Microbiol. 57:2351-2359. 
15. Ghorbani, R., Wilockson, S., Koocheki, A., and Leifert, C. 2008. Soil management for sustainable crop disease control: a review. Environ. Chem. Lett. 6:149-162.

16. Glimm, E., Heuer, H., Engelen, B., Smalla, K., and Backhaus, H. 1997. Statistical comparisons of community catabolic profiles. J. Microbiol. Methods 30:71-80.

17. Goicoechea, N. 2009. To what extent are soil amendments useful to control Verticillium wilt? Pest Manage. Sci. 65:831-839.

18. Kabir, Z., Bhat, G., and Subbarao, K. V. 2004. Comparison of media for recovery of Verticillium dahliae from soil. Plant Dis. 88:49-55.

19. Ladygina, N., and Hedlund, K. 2010. Plant species influence microbial diversity and carbon allocation in the rhizosphere. Soil Biol. Biochem. 42:162-168.

20. Larkin, R. P. 2003. Characterization of soil microbial communities under different potato cropping systems by microbial population dynamics, substrate utilization, and fatty acid profiles. Soil Biol. Biochem. 35:1451-1466.

21. Larkin, R. P. 2008. Relative effects of biological amendments and crop rotations on soil microbial communities and soilborne diseases of potato. Soil Biol. Biochem. 40:1341-1351.

22. Larkin, R. P., and Griffin, T. S. 2007. Control of soilborne diseases of potato using Brassica green manures. Crop Prot. 26:1067-1077.

23. Larkin, R. P., and Honeycutt, C. W. 2006. Effects of different 3-year cropping systems on soil microbial communities and Rhizoctonia diseases of potato. Phytopathology 96:68-79.

24. Larkin, R. P., Hopkins, D. L., and Martin, F. N. 1993. Ecology of Fusarium oxysporum f. sp. niveum in soils suppressive and conducive to Fusarium wilt of watermelon. Phytopathology 83:1105-1116.

25. Larkin, R. P., Griffin, T. S., and Honeycutt, C. W. 2010. Rotation and cover crop effects on soilborne potato diseases, tuber yield, and soil microbial communities. Plant Dis. 94:1491-1502.

26. Larkin, R. P., Honeycutt, C. W., Griffin, T. S., Olanya, O. M., Halloran, J. M., and He, Z. 2011. Effects of different potato cropping system approaches and water management on soilborne diseases and soil microbial communities. Phytopathology 101:58-67.

27. Lazarovits, G. 2010. Managing soilborne diseases of potatoes using ecologically based approaches. Am. J. Potato Res. 87:401-411.

28. Lazarovits, G., and Subbarao, K. 2010. Challenges in controlling Verticillium wilt by the use of nonchemical methods. In: Recent Developments in Management of Plant Diseases. U. Gisi, I. Chet, and L. Gullino, eds. Springer, Dordrecht, The Netherlands.

29. Manici, L. M., and Caputo, F. 2009. Fungal community diversity and soil health in intensive potato cropping systems of the east Po valley, northern Italy. Ann. Appl. Biol. 155:245-258.

30. Matthiessen, J. N., and Kirkegaard, J. A. 2006. Biofumigation and enhanced biodegradation: opportunity and challenge in soilborne pest and disease management. Crit. Rev. Plant Sci. 25:235-265.

31. Mazzola, M., Granatstein, D. M., Elfving, D. C., and Mullinix, K. 2001.
Suppression of specific apple root pathogens by Brassica napus seed meal amendment regardless of glucosinolate content. Phytopathology 91:673 679.

32. McGuire, A. N. 2003. Mustard green manures replace fumigant and improve infiltration in potato cropping system. Crop Manage. Online. doi 10.1094/CM-2003-0822-01-RS

33. Ochiai, N., Crowe, F. J., Dick, R. P., and Powelson, M. L. 2007. Effects of green manure type and amendment rate on Verticillium wilt severity and yield of Russet Burbank potato Plant Dis. 91:400-406.

34. Pegg, G. F., and Brady, B. L. 2002. Verticillium Wilts. CABI Publishing, CABI International, Wallingford, UK.

35. Perez, C., Dill-Macky, R., and Kinkel, L. L. 2008. Management of soil microbial communities to enhance populations of Fusarium graminearumantagonists in soil. Plant Soil 302:53-69.

36. Rowe, R. C., Curwen, D., and Potato Association of America. 1993. Potato Health Management, Plant health management series. American Phytopathological Society, St. Paul, MN..

37. Rowe, R. C., and Powelson, M. L. 2002. Potato early dying: management challenges in a changing production environment. Plant Dis. 86:1184-1193.

38. Sarwar, M., Kirkegaard, J. A., Wong, P. T. W., and Desmarchelier, J. M. 1998. Biofumigation potential of Brassicas. III. In vitro toxicity of isothiocyanates to soil-borne fungal pathogens. Plant Soil 210:103-112.

39. Sexton, P., Plant, A. B., Johnson, S. B., and Jemison, J. 2007. Effect of a mustard green manure on potato yield and disease incidence in a rainfed environment. Crop Manage. Online. doi:10.1094/CM-2007-0122-02-RS

40. Smolinska, U., and Horbowicz, M. 1999. Fungicidal activity of volatiles from selected cruciferous plants against resting propagules of soil-borne fungal pathogens. J. Phytopathol. 147:119-124.

41. Soltani, N., Conn, K. L., Abbasi, P. A., and Lazarovits, G. 2002. reduction of potato scab and Verticillium wilt with ammonium lignosulonate soil amendment in four Ontario potato fields. Can. J. Plant Pathol. 24:332-339.

42. Stevenson, W. R., Loria, R., Franc, G. D., and Weingartner, D. P. 2001 Compendium of Potato Diseases, 2nd ed. W. R. Stevenson, ed. American Phytopathological Society, St. Paul, MN.

43. Subbarao, K. V., Hubbard, J. C., and Koike, S. T. 1999. Evaluation of broccoli residue incorporation into field soil for Verticillium wilt control in cauliflower. Plant Dis. 83:124-129.

44. Welbaum, G. E., Sturz, A. V., Dong, Z., and Nowak, J. 2004. Managing soil microorganisms to improve productivity of agro-ecosystems. Crit. Rev. Plant Sci. 23:175-193

45. Wiggins, B. E., and Kinkel, L. L. 2005. Green manures and crop sequences influence potato diseases and pathogen inhibitory activity of indigenous streptomycetes. Phytopathology 95:178-185.

46. Zelles, L., Bai, Q. Y., Rackwitz, R., Chadwick, D., and Beese, F. 1995 Determination of phospholipid- and lipopolysaccharide-derived fatty acids as an estimate of microbial biomass and community structures in soils. Biol Fertil. Soils 19:115-123. 